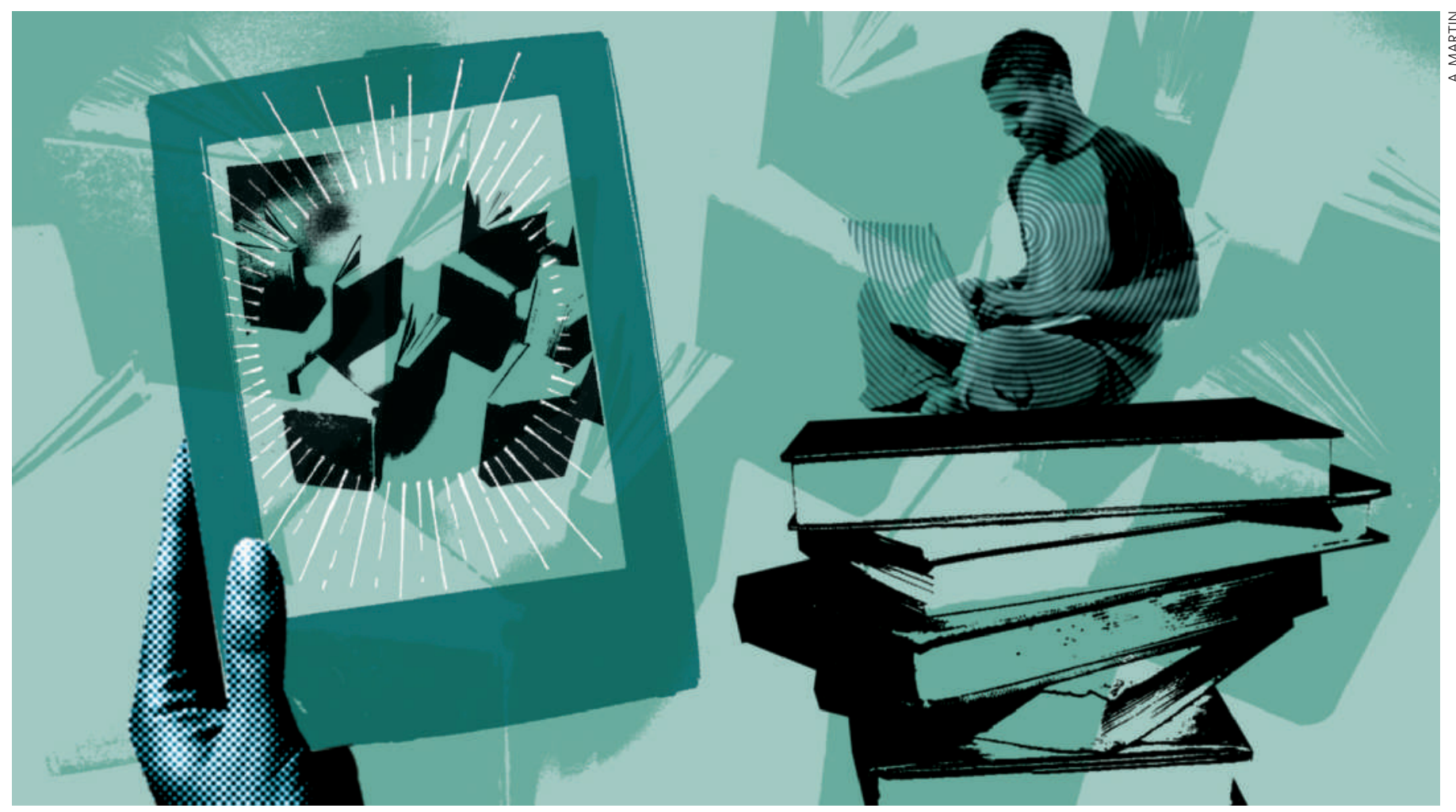

\title{
The textbook of the future
}

\section{Undergraduate textbooks are going digital. Declan Butler asks how this will shake up student reading habits and the multi-billion-dollar print textbook market.}

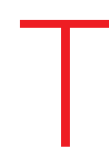

he rumble of textbooks thumping on to the desks of a university lecture theatre, the rustle of turning pages, the groan of backpack straps hoisting 10 kilograms of textbooks - these sounds may soon be an echo of the past. This semester, 1,200 students at the University of Texas at Austin (UTA) are foregoing printed textbooks in a pilot trial of Amazon Kindle e-readers stuffed with texts in electronic form. At NorthWest Missouri State University (NWMSU) in Maryville, classes are testing textbooks on Sony e-readers, as well as on the students' own laptops, as part of plans to roll out e-textbooks across all courses within 5 years. The list goes on: within the past 18 months or so, as textbook publishers have begun to make more and more titles available online, universities worldwide have begun to experiment with e-textbooks.

"E-textbooks are not yet mainstream - but they are on the edge of a breakthrough into the mainstream," says Kevin Hegarty, UTA chief financial officer. Indeed, textbook publishers are scrambling to position themselves for a revolution in the way they do business as they rethink their decades-old model of massive, printed tomes sold at premium prices.

The resulting proliferation of new models none of which is yet a sure winner - is being shaped by the interplay of at least three forces: new e-readers and displays for viewing and interacting with the e-textbook content; new business and licensing models for delivering quality content at prices students and universities can afford; and new concepts for the content itself, and for how it is created.

\section{Beyond black and white}

On the hardware front, e-textbooks are reaping the benefits of rapid innovation in electronic readers for documents and novels. Most of the latest generation of e-readers, such as Amazon's Kindle 2 and Sony's PRS-700, offer displays based on technology from the E-Ink Corporation of Cambridge, Massachusetts (see Nature doi:10.1038/news.2009.202; 2009). These displays produce text and images that rival the brightness and clarity of ink on paper, which makes reading them far more comfortable than reading text on the liquid crystal display screens of laptops and desktop computers. They also allow an e-reader's batteries to last for days: the displays require power only when the screen is being changed - for example, by 'turning' a page. The first generation of such e-readers, launched less than three years ago, has already sparked mass uptake of e-books, and they could potentially do the same for e-textbooks.

As delivery vehicles for textbooks, however, existing e-readers still leave a lot to be desired. For example, most are designed for reading books from beginning to end. But "very few students read a textbook in that manner", says Paul Klute, who is directing the NWMSU e-textbook project. He recalls how the school launched its pilot test of the Sony's PRS-505 reader in autumn 2008 with e-textbooks from six publishers. It was an instant flop with the 200 student testers. They wanted to do what they had always done, says Klute, and flip through to find bits they didn't grasp in the lecture, or dip in to read short sections, or find a key figure. But the e-reader wasn't built for this, so they ended up frustrated. This semester, 
Sony has replaced the device with the newer PRS-700. Its search and navigation functions and the ability to flip a page by swiping a finger across the touch screen have elicited a much more positive response, Klute says.

Another drawback of current e-readers is that they have small black-and-white displays, just a little larger than 9 by 12 centimetres. This makes them unsuited to most science textbooks, which typically have large pages and colourful graphics. "The market is not likely to expand until the e-readers improve," says Hegarty.

Many large textbook companies are holding off from experimenting with e-readers until that happens. But manufacturers promise that big screen, colour e-readers are on the way within a year or two. If so, this will be the tipping point at which e-textbooks take off, predicts Hegarty. "It will be a big leap forwards," he says.

If the price is right. Dedicated e-readers currently start at prices of around US\$350, points out Joe Esposito, a digital-media consultant and former chief executive of Encyclopaedia Britannica online. Reading an e-textbook on a laptop might not be as easy on the eyes, but most students already own a laptop - complete with a colour display. "The student laptop will prove a potent competitive entry barrier to other devices for reading e-textbooks," says Esposito. This is why NWMSU is also piloting e-textbooks on laptops among 500 students in 11 disciplines in an effort to compare how well students learn with e-readers, laptops and print textbooks.

That is probably a wise approach. Five years ago, devices such as the Kindle did not even exist. Which devices students will use for reading e-textbooks five years from now is anybody's guess - although many people are betting on some sort of convergent evolution among

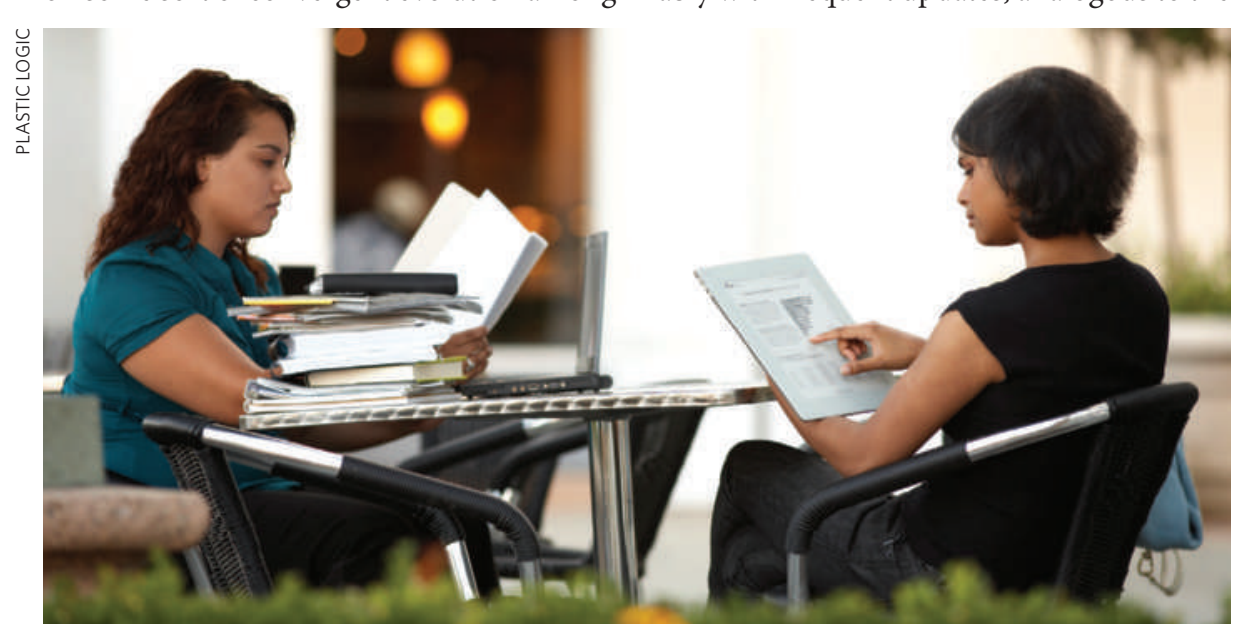

Students say they would prefer to have print textbooks - until they are offered a cheaper option.

e-readers, laptops, portable music players and smart phones. The boundaries will increasingly blur, predicts Neelan Choksi, co-founder and chief operating officer of Lexcycle, a company based in Portland, Oregon, that makes Stanza, a popular e-book reader application for the iPhone. "Everyone is racing to be the ultimate multi-function device," he says.

\section{Kindling a revolution}

But device innovation has other implications as well. Just as the Internet brought dramatic change to the music industry, which relied on selling content on a physical medium, such as the $\mathrm{CD}$, better devices could similarly disrupt the textbook industry. So it is not surprising that textbook publishers' embrace of e-textbooks is reminiscent of two scorpions mating.

Like the music industry, textbook publishers have been reluctant to put content online because of concerns about piracy, and the risk that it might undermine sales of their traditional print editions. If they are now willing to do so, it is largely because such concerns have been offset by the realization that e-textbooks may give them a way to cut into the largest threat to their profits: the huge market for second-hand textbooks.

Thanks to the Internet, what was once the preserve of local used bookstores is now a vast and sophisticated international online market. The US market for new textbooks is estimated at around $\$ 5.5$ billion, but the parallel market for used books is around one-third of that, says Esposito. Publishers hope that by offering lower priced e-textbooks they can obliterate the used-textbook market, from which they currently get nothing, and sell electronic versions semester after semester - presumably with frequent updates, analogous to the

(c) 2009 Macmillan Publishers Limited. All rights reserved

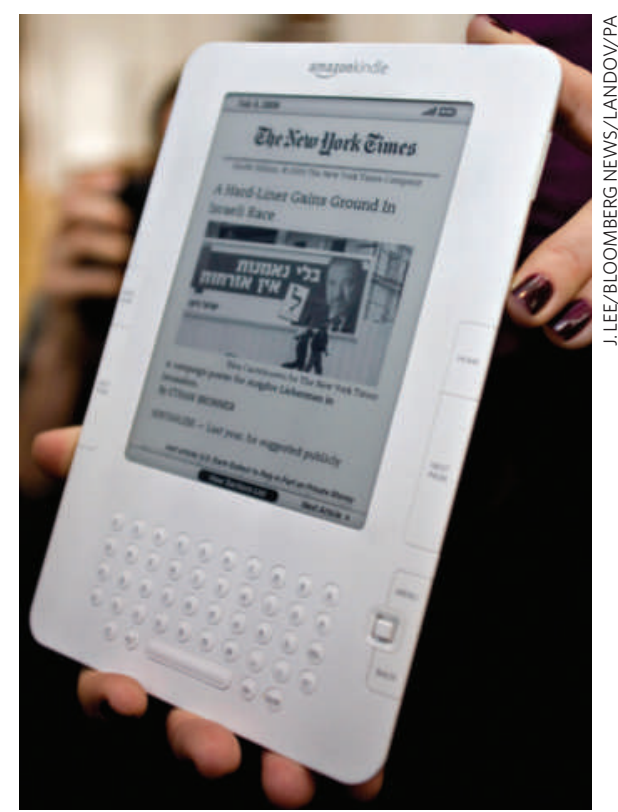

Amazon's Kindle: bringing technology to book.

new print editions they regularly bring out.

But publishers' enthusiasm for e-textbooks remains relative, says Esposito. "E-textbooks are too big a market for publishers to walk away from, but publishers are not willing to walk away from the print market that makes up more than $90 \%$ of their sales." This defence of the print market is reflected in their offerings, which are usually electronic facsimiles of printed textbooks, sold to students online, and which provide only the most basic functionality, such as printing, highlighting and making electronic annotations.

By far the largest market for textbooks is the United States, and the companies that win in this space are also likely to be those that will dominate worldwide. Because of this, it is also likely to be where the evolution of e-textbook business models plays out.

The biggest player is CourseSmart, a consortium in Belmont, California, created by the five publishers who together account for roughly $85 \%$ of the global print textbook market: Pearson; Cengage Learning; McGrawHill Education; John Wiley \& Sons; and the Bedford, Freeman \& Worth Publishing Group. (The last is a unit of Macmillan, which is owned by Nature's parent company, the Georg von Holtzbrinck Publishing Group based in Stuttgart, Germany.) "We have brought a critical mass of textbooks together on a single common platform for the first time," says Sean Devine, chief executive of CourseSmart.

CourseSmart sells its e-textbooks at about half the price of its print versions, and so far has made more than 5,800 e-textbooks available at its website, or about one-third of the world's 
most popular textbooks. Students who buy the books are constrained by digital rights management. The copy they buy usually 'expires' after their course has ended, after which it no longer accessible. CourseSmart's digital rights management also forbids students from moving a book downloaded on one computer to another device, limits printing to 10 pages at a time, and allows the whole book to be printed only once.

\section{Bulk buying}

Nonetheless, student purchases of CourseSmart e-textbooks are growing rapidly, says Devine. A survey by NWMSU in February found that, all things being equal, about half the students would prefer print textbooks and about a quarter would prefer e-textbooks, whereas the remainder had no strong feeling. But when asked what they would do if buying a textbook themselves, almost $80 \%$ said they would opt for the cheaper e-textbook offering.

Ongoing tests of CourseSmart e-textbooks by the University System of Ohio show that they reduce costs - the average US student forks out some $\$ 900$ annually on print textbooks - and students using them perform just as well as when using paper versions, says Peter Murray, deputy head of new service development at the Ohio Library and Information Network in Columbus, Ohio, which assists the University System of Ohio on the project.

But Make Textbooks Affordable, a coalition of US student groups, thinks that students are being fleeced, and that the price of 'renting' an electronic file, which costs little for publishers to distribute, is excessive. Indeed, if an e-textbook typically costs half that of the print version, the saving is less impressive when one considers that buyers of new print books would recoup much the same
"Cheap prices are the most effective digitalrights management."

- Eric Frank

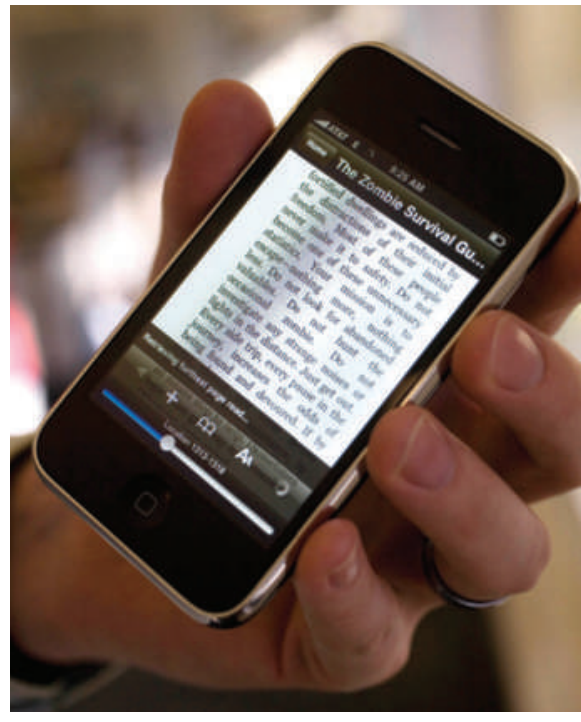

The multi-function iPhone: one ring to rule them all?

hardcopy books," he says.

Klute also favours such a scheme. NWMSU already spends around $\$ 800,000$ a year on tens of thousands of copies of print textbooks that it rents to students, who are charged $\$ 80-\$ 90$ per semester for textbook provision. He thinks that using an e-textbook site licence could at least halve that cost to students.

Such a model is being tested by the UK National E-books Observatory project. The project has licensed from publishers 36 e-textbooks in business and management, medicine, media studies and engineering from September 2007 to August 2009 at a cost of $£ 600,000$, and made them available free to all UK universities. It is the future, says Liam Earney, collections team manager of the Joint Information Systems Committee, based in London - a body established by by reselling, and students might pick up used versions for the same price or less.

Charging half the price of a printed textbook for an e-book that expires is "far too costly", says Hegarty. Rather than leaving students to act as isolated agents in the marketplace, he says, universities, or consortia of universities, should step in and use their bulk-purchasing clout to force down prices by negotiating site licences to e-textbooks, just as many do for online versions of scientific journals. E-textbooks procured this way could be made free at the point of use to all on campus, or for flat fees included in tuition fees. "The winning model will involve licensing content broadly such that the library licenses the materials, the professors assigns them and the student electronically checks them out of the library as they do
Britain's higher-education funding councils to support education by promoting technological innovation - which operates the pilot.

\section{Open source}

A more radical idea is to offer textbooks for free, without rights restrictions. A range of free, open textbooks are already available for download at WikiBooks (http://en.wikibooks. org); the Community College Consortium for Open Educational Resources' Open TextBooks Project; and Connexions, created in 1999 by electrical engineer Richard Baraniuk of Rice University in Houston Texas. These texts typically take the form of modules written by many expert authors.

For now these free textbooks remain a cottage industry, says Esposito. Wikipedia-like volunteer efforts are much better suited to self-contained modules that are small enough for an individual to see through from $\mathrm{A}$ to $\mathrm{Z}$. But a textbook demands a coherent overall $\underset{\Sigma}{\Sigma}$ structure and coordination between sections. That is why creating one has always been a major undertaking, demanding long-term commitments by publishers - who need to make a profit - and by authors who usually want to be paid for their effort.

Still, perhaps 'free' and 'profitable' need not be a contradiction in terms. One group of veteran textbook publishing executives is trying to put open textbooks on a solid commercial footing. In 2007 they created Flat World Knowledge, based in Nyack, New York, and in January 2009 rolled out the first of the 21 textbooks they have in development so far. The texts are written by some 40 domain experts who will be paid $20 \%$ of royalties. The company also plans to make its content available via Kindle and other e-readers. All its content will be free to reuse for non-commercial purposes under a creative commons licence.

Eric Frank, Flat World's co-founder, says that the strategy is to attract greater use by giving the e-textbooks away - the initial targets are the high-volume texts for first-year students - and then look for profit from students' purchase of print-on-demand versions at $\$ 29.95$ for black and white, and $\$ 59.95$ for colour. Students can copy and use the electronic content in any way they wish, says Frank. "Cheap prices are the most effective digital-rights management," he says. "We want to avoid a digital-rights war with students." The company also hopes to make money by licensing its content to commercial companies, such as distance-learning outfits and course-management software firms.

By making its content free for reuse, Flat World Knowledge will allow lecturers to splice and dice its content. "More and more professors want to teach from 'customized' textbooks, which are aggregations of various materials, not just what a publisher has aggregated in a single book," says Hegarty. He says that the UTA has made an electronic tool available for academics to aggregate any licensed library materials, including scientific journals, and 'publish' them to their students as their textbook materials. "I think that this is where textbooks are headed."

In the larger sense, of course, no one really knows where e-textbooks are headed. They just know that things are moving very fast. About all that's certain, says Klute, is that the next chapter of e-textbooks is now being written. "E-textbooks as we currently know them will look drastically different five years from now".

Declan Butler is a senior reporter at Nature, based in France.

See Editorial, page 549. 